\section{Correlation of Bedside Ultrasonographic Measurement of IVC Diameter and Caval Index with CVP in Spontaneously Breathing and Mechanically Ventilated Patients}

Keywords: CVP; Hemodynamic monitoring; Caval index; IVC diameter.

\begin{abstract}
Background: One of the important parameters in the hemodynamic evaluation of critically ill patients is central venous pressure (CVP). Sonographic measurement of the inferior vena cava (IVC) diameter and caval index (IVC collapsibility index) is a non-invasive method of estimating the fluid status in critically ill patients. In this study, we aimed to detect the correlation between IVC diameter and caval index with CVP in both spontaneously breathing and mechanically ventilated patients.

Methods: The anterior posterior diameter of the IVC just caudal to the confluence of the hepatic veins was measured during inspiration and expiration to calculate the IVC diameter and caval index. CVP was detected in $\mathrm{cm} \mathrm{H} 2 \mathrm{O}$.

Results: As regard correlation between IVC measurements (IVC diameter and caval index) and CVP, regression coefficients were higher among spontaneously breathing than mechanically ventilated patients. In sedated patients, the mean difference between inspiratory and expiratory IVC diameter is not of clinical significance. The mode of mechanical ventilation and peak inspiratory pressure were insignifican in prediction of CVP.

Conclusion: Ultrasonographic assessment of IVC diameter and cava index seems to be a simple and non-invasive method to assess the fluid status in spontaneously breathing patients but its use in mechanically ventilated patients is not helpful.
\end{abstract}

\section{Introduction}

Evaluation of intravascular volume status in critically ill patients is very essential. Central venous catheter insertion is needed to determine the CVP which is used to detect the fluid need. Complications such as arrhythmias, pneumothorax, haemothorax, hematoma, infection and thrombosis may occur with catheter insertion [1]. Sonographic evaluation of the IVC diameter and its usefulness in evaluating the volume status are studied and documented [2]. Ultrasound imaging has several advantages; it is simple, noninvasive and can be used for repeated assessment. Ultrasound units are present in most intensive care units to routinely perform the focused assessment sonography in critically ill patients [3]. The IVC is a thin-walled and compliant vessel. By changing its diameter, it adjusts to the body's volume status. Inspiration generates negative pressure which results in increase venous return, subsequently collapsing the IVC. Expiration decreases venous return and the IVC diameter returns to its original value. In cases of decreased intravascular volume, the degree of IVC

\section{Journal of}

Emergency Medicine \& Critical Care

\author{
Heba Wagih Abdelwahab ${ }^{1 *}$ and Reham Abd El-Wahab ${ }^{2}$ \\ ${ }^{I}$ Chest medicine department, Mansoura University, Egypt \\ Radiology department, Mansoura University, Egypt \\ Address for Correspondence \\ Heba Wagih Abdelwahab, Chest Medicine Department, Mansoura \\ University, Egypt, Tel: 00201000670365; Email: Wagihheba84@ \\ gmail.com \\ Submission: 08 November, 2017 \\ Accepted: 06 December, 2017 \\ Published: 16 December, 2017 \\ Copyright: ( $) 2017$ Abdelwahab HW, et al. This is an open access article \\ distributed under the Creative Commons Attribution License, which \\ permits unrestricted use, distribution, and reproduction in any medium, \\ provided the original work is properly cited.
}

collapse will be proportionally higher than in cases with increased intravascular volume. The IVC collapsibility is determined by the calculation of the caval index (\%) [4]. In this study, we aimed to detect the correlation between IVC diameter and caval index with CVP in spontaneously breathing and mechanically ventilated patients to provide IVC assessment as a guiding method in evaluation of the intravascular volume status.

\section{Methods}

Patients admitted to critical care unit and whom a central venous catheter was inserted was included in the study. However, Patients refuse to participate in the study, presence excessive bowel gas or obese patients were excluded.

\section{The IVC diameters and caval index measurement}

To measure the IVC diameter, a curvilinear probe of the Mind ray ultrasound device will be placed in the subxiphoid region (in the longitudinal plane) to visualize the point at which hepatic veins empties in the IVC. Localization of the heart was done by cranial angulation of the ultrasound probe in this plane. The maximum internal anterior posterior diameter of the IVC just caudal to the confluence of the hepatic veins $(2-3 \mathrm{~cm}$ from the border of the right atrium) was measured in millimeters at the end of inspiration and expiration.

Caval index (\%) measured as following:

IVC expiratory diameter - IVC inspiratory diameter/ IVC expiratory diameter $\times 100$

\section{Central venous pressure measurement}

The reference point (level of the right atrium=zero point) was taken at the level of the fourth costal cartilage in mid-axillary line. CVP measurements were hidden about the clinician who will perform IVC measurements. The measures of CVP were recorded in $\mathrm{cmH} 20$.

\section{Statistical analysis}

SPSS V.16 was used in the analysis of data. For correlation, Pearson and spearman tests were used. 
Citation: Abdelwahab HW, El-Wahab RA. Correlation of Bedside Ultrasonographic Measurement of IVC Diameter and Caval Index with CVP in Spontaneously Breathing and Mechanically Ventilated Patients. J Emerg Med Critical Care 2017;3(1): 2.

\section{Results}

120 patients were enrolled. 57 (47.5\%) patients were males. 43 patients had subclavian catheter and 77 patients had jugular catheter. $66(55 \%)$ patients required mechanical ventilation while $54(45 \%)$ patients were spontaneously breathing. 38 (57.6\%) of mechanically ventilated patients received volume mode and 28 (23.3\%) received pressure mode. Table 1 shows the distribution of the patient's diagnosis. CVP values and its corresponding IVC diameter and caval index measurements in mechanically ventilated and spontaneously breathing patients are shown in Table 2.

As regard the correlation between IVC measurements (IVC diameter and caval index) and CVP

Although a statistically significant correlation was found between IVC measurements (IVC diameter and caval index) and CVP in both spontaneously breathing and mechanically ventilated patients $(\mathrm{p}<0.001)$, regression coefficients were higher among spontaneously breathing ( $\mathrm{r}=0.74$ for IVC diameter and -0.76 for caval index) than mechanically ventilated patients $(\mathrm{r}=0.4$ for IVC diameter and -0.47 for caval index) (Table 3).

In deeply sedated mechanically ventilated patients, the mean difference between inspiratory and expiratory IVC diameter was $(3 \pm 1.3 \mathrm{~mm})$ which is not of clinical significance. IVC diameter increases with inspiration. Linear regression model showed mode of mechanical ventilation (pressure or volume mode) and peak inspiratory pressure (PIP) were insignificant in prediction of CVP $(\mathrm{r}=0.13, \mathrm{p}=0.29)$.

Table 1: The number and the percentage distribution of the patient's diagnosis.

\begin{tabular}{|c|c|}
\hline Total number of patients enrolled $(\mathbf{n})$ & 120 \\
\hline Patients characteristics: & 120 \\
\hline Total number of patients enrolled $(\mathrm{n})$ & Males $(\mathrm{n}=57)$ \\
\hline Gender & Females $(\mathrm{n}=63)$ \\
\hline Age (mean \pm SD) & $47 \pm 6$ \\
\hline Diagnosis & $\mathrm{n}(\%)$ \\
\hline Pneumonia & $75(62.5)$ \\
\hline Chronic obstructive pulmonary disease & $22(18.3)$ \\
\hline Pulmonary embolism & $3(2.5)$ \\
\hline Heart failure & $7(5.8)$ \\
\hline Pleural effusion & $11(9.2)$ \\
\hline Bronchial asthma & $2(1.7)$ \\
\hline
\end{tabular}

Table 2: CVP values and its corresponding IVC diameter and caval index measurements.

\begin{tabular}{|c|c|c|c|c|}
\hline \multirow{3}{*}{ CVP } & \multirow{2}{*}{\multicolumn{2}{|c|}{\begin{tabular}{|c|} 
IVC expiratory diameter $(\mathrm{mm})$ \\
mean $(\mathrm{SD})$
\end{tabular}}} & \multirow{2}{*}{\multicolumn{2}{|c|}{$\begin{array}{c}\text { Caval index (\%) } \\
\text { mean (SD) }\end{array}$}} \\
\hline & & & & \\
\hline & $\begin{array}{c}\text { Spontaneous } \\
\text { breathing }\end{array}$ & $\begin{array}{l}\text { Mechanical } \\
\text { ventilation }\end{array}$ & $\begin{array}{c}\text { Spontaneous } \\
\text { breathing }\end{array}$ & $\begin{array}{l}\text { Mechanical } \\
\text { ventilation }\end{array}$ \\
\hline$<8 \mathrm{cmH}_{2} \mathrm{O}$ & $10.7( \pm 3.7)$ & $17( \pm 3.3)$ & $70.1( \pm 7)$ & $52.9( \pm 23.6)$ \\
\hline $8-12 \mathrm{cmH}_{2} \mathrm{O}$ & $14.4( \pm 6.2)$ & $18.8(4.5)$ & $61.5( \pm 17.8)$ & $41.2( \pm 25.8)$ \\
\hline$>12 \mathrm{cmH}_{2} \mathrm{O}$ & $21.2( \pm 5.9)$ & $20.8(5.2)$ & $35.4( \pm 17.2)$ & $27.6( \pm 18.2)$ \\
\hline
\end{tabular}

Table 3: Correlation of IVCD, caval index with CVP.

\begin{tabular}{|c|c|c|}
\hline & $\begin{array}{c}\text { Spontaneous } \\
\text { breathing }(n=54)\end{array}$ & $\begin{array}{l}\text { Mechanical ventilation } \\
(n=66)\end{array}$ \\
\hline IVCD expiratory & $r=0.74, p<0.001$ & $r=0.4, p=0.001$ \\
\hline IVCD inspiratory & $r=0.78, p<0.001$ & $r=0.46, p<0.001$ \\
\hline Caval index & $r=-0.76, p<0.001$ & $r=-0.47, p<0.001$ \\
\hline
\end{tabular}

\section{Discussion}

In this study, a significant relationship was found between CVP and sonographic IVC measurements (IVC diameter and caval index) in spontaneously breathing patients. However, this correlation was weak in mechanically ventilated patients whatever the mode (volume or pressure) and peak inspiratory pressure level. In accordance to these results, Citilcioglu S et al. 2014 also concluded that IVC diameter may be used for assessment of the intravascular volume status of spontaneously breathing patients but not accurate measure in mechanically ventilated patients [5]. Lorsomradee $S$ et al. found strong correlation between IVC diameter and CVP (when CVP was $\leq 11 \mathrm{mmHg}$ ) in cardiac surgical patients [6]. In deeply sedated mechanically ventilated patients in this study, the mean difference between inspiratory and expiratory IVC diameter was $(3 \pm 1.3 \mathrm{~mm})$ which is not of clinical significance and could describe the weak correlation between IVC measurements (IVC diameter and caval index) and CVP in mechanically ventilated patients. Therefore, Measurement of IVC diameter in mechanically ventilated patients cannot accurately predict right atrial pressure. However, Feissel $\mathrm{M}$ et al. reported that respiratory variation in IVC diameter $(\triangle \mathrm{IVC}=$ maximum-minimum diameters/the mean of both) is a simple method to determine fluid responsiveness in deeply sedated mechanically ventilated patients with septic shock and received a tidal volume $\geq 8 \mathrm{~mL} / \mathrm{kg}$ [7]. Also, Naghipour B et al. found acceptable correlation between the IVC diameter and CVP but at the level of IVC entry into the right atrium using transesophageal echocardiography [8].

\section{Conclusion}

Ultrasonographic assessment of IVC diameter and caval index seems to be a simple and non invasive method to assess the fluid status in spontaneously breathing patients but its use in mechanically ventilated patients is not helpful.

\section{References}

1. Johansson E, Hammarskjöld F, Lundberg D, Arnlind MH (2013) Advantages and disadvantages of peripherally inserted central venous catheters (PICC) compared to other central venous lines: a systematic review of the literature. Acta Oncol 52: 886-892.

2. Krause I, Birk E, Davidovits M, Cleper R, Blieden L, et al. (2001) Inferior vena cava diameter: a useful method for estimation of fluid status in children on hemodialysis. Nephrol Dial Transplant 16: 1203-1206.

3. Carr BG, Dean AJ, Everett WW, Ku BS, Mark DG, et al. (2007) Intensivist bedside ultrasound (INBU) for volume assessment in the intensive care unit: a pilot study. J Trauma 63: 495-502.

4. Goldflam K, Saul T, Lewiss R (2011) Focus on: inferior vena cava ultrasound. ACEP News.

5. Citilcioglu S, Sebe A, Ay MO, Icme F, Avci A, et al. (2014) The relationship between inferior vena cava diameter measured by bedside ultrasonography and central venous pressure value. Pak J Med Sci 30: 310-315.

6. Lorsomradee S, Lorsomradee S, Cromheecke S, ten Broecke PW, De Hert SG (2007) Inferior vena cava diameter and central venous pressure correlation during cardiac surgery. J Cardiothorac Vasc Anesth 21: 492-496.

7. Feissel M, Michard F, Faller JP, Teboul JL (2004) The respiratory variation in inferior vena cava diameter as a guide to fluid therapy. Intensive Care Med 30: 1834-1837.

8. Naghipour B, Faridaalaee G (2016) Correlation between central venous pressure and inferior vena cava sonographic diameter; determining the best anatomic location . Emerg (Tehran) 4: 83-87. 